\title{
A Facile Plant Mediated Synthesis of Magnetite Nanoparticles Using Aqueous Leaf Extract of Ficus hispida L. for Adsorption of Organic Dye
}

\author{
*A.V.Ramesh ${ }^{1}$, B.Lavakusa ${ }^{1}$, B. Satish Mohan ${ }^{1}$, Y. Pavan Kumar ${ }^{1}$, \\ D.RamaDevi ${ }^{2}$, K.Basavaiah $^{1}$ \\ ${ }^{I}$ Department Of Inorganic \& Analytical Chemistry, Andhra University Visakhapatnam-530003, India. \\ ${ }^{2}$ A.U. College Of Pharmaceutical Sciences, Andhra University, Visakhapatnam-530003, India.
}

\begin{abstract}
A facile and eco-friendly method for the synthesis of magnetite nanoparticles ( $\mathrm{Fe}_{3} \mathrm{O}_{4} \mathrm{NPs}$ ) via CoPrecipitation in the presence of aqueous leaf extract of Ficus hispida L. The optical, crystalline, structural morphology and magnetic behaviour of the synthesized $\mathrm{Fe}_{3} \mathrm{O}_{4} \mathrm{NPs}$ were characterized by Ultraviolet-Visible $(U V$-Vis), Fourier transform infrared (FTIR) spectroscopy, powder X-ray diffraction (XRD), field emission scanning electron microscopy (FESEM), and transmission electron microscopy (TEM) and vibrating sample magnetometer (VSM). The absorption spectrum reveals the peak at $379 \mathrm{~nm}$, which confirm the formations of $\mathrm{Fe}_{3} \mathrm{O}_{4} \mathrm{NPs}$. XRD results reveals the formation of phase pure $\mathrm{Fe}_{3} \mathrm{O}_{4} \mathrm{NPs}$ with cubic inverse spinel structure with crystallite sizes of $11.04 \mathrm{~nm}$. The FESEM and TEM images clearly show that the spherical shape of $\mathrm{Fe}_{3} \mathrm{O}_{4} \mathrm{NPs}$ with average particles size of $10.96 \mathrm{~nm}$. Bright circular rings in the selected area electron diffraction (SAED) pattern showed good crystallinity. VSM results show super paramagnetic behaviour of $\mathrm{Fe}_{3} \mathrm{O}_{4} \mathrm{NPs}$. The synthesized $\mathrm{Fe}_{3} \mathrm{O}_{4} \mathrm{NPS}$ have potential to adsorption of Methylene Blue(MB)
\end{abstract}

Keywords: Magnetite nanoparticles, Green Synthesis, Ficus hispida L. leaf, Methylene Blue dye.

\section{Introduction}

During the past two decades metal oxide nanomaterials have attracted a great attention due to their unique optical, electrical, magnetic and electronic properties[1].Especially, the magnetic metal oxide nanoparticles received much attention for a wide range of applications such as catalysis, biosensors, ferrofluids, high density magnetic storage media, separation and purification of biomolecules[2-6]. Among all magnetic metal oxides, magnetite $\left(\mathrm{Fe}_{3} \mathrm{O}_{4}\right)$ have emerged potential candidates for advance technological applications due to their low toxicity, biocompatibility and super paramagnetic behaviour [7-9]. Upto now, various morphologies, such as nanorods, nanowires, nanofibers, nanoflowers, nanotubes, nano cage, and nanoparticles have been prepared for $\mathrm{Fe}_{3} \mathrm{O}_{4}$ NPs by several chemical and physical approaches such as Co-Precipitation, hydrothermal, thermal decomposition of iron carbonyls, poloyl, electrochemical deposition, spray and laser pyrolysis and sono chemical method [10-20]. In all these methods, synthesis of $\mathrm{Fe}_{3} \mathrm{O}_{4}$ NPs uses toxic or potentially hazardious materials and requires more energy. Moreover, $\mathrm{Fe}_{3} \mathrm{O}_{4} \mathrm{NPs}$ can easily aggregated below their critical particle size and limits their applications. Numerous approaches have been reported for the preparation of aggregate free $\mathrm{Fe}_{3} \mathrm{O}_{4}$ NPs by the use of surface capping agents such as polymers, long chain organic capping agents. However, these capping agents have a potential toxicity to the environment and public health. Therefore, it is highly desirable to develop simple bio-compatible and green methods for synthesis of $\mathrm{Fe}_{3} \mathrm{O}_{4}$ NPs. More recently, use of biomaterials such as microbial, fungi and plant extracts for the preparation of variety of metal oxide nanoparticles due to their nontoxic nature and eco-friendly. The plant extract assisted synthesis of $\mathrm{Fe}_{3} \mathrm{O}_{4} \mathrm{NPs}$ has been quite limited and few plant extracts mediated works have been reported. For example, Tridax procumbens, Artemisia апnиa, leaf extract of Perilla frutescens and caricaya papaya and also seed extract of grape proanthocyanidin [21-25] .So far no reports were available for synthesis of $\mathrm{Fe}_{3} \mathrm{O}_{4} \mathrm{NPs}$ using the aqueous leaf extract of Ficus hispida L. In this work, for the first time, we have synthesized $\mathrm{Fe}_{3} \mathrm{O}_{4} \mathrm{NPs}$ via plant mediated green synthesis approach using aqueous leaf extract of Ficus hispida $\mathrm{L}$. The synthesis carried out in an aqueous medium, aqueous leaf extract of Ficus hispida L. act as reducing and capping agent for $\mathrm{Fe}_{3} \mathrm{O}_{4}$ NPs. As prepared $\mathrm{Fe}_{3} \mathrm{O}_{4}$ NPs using aqueous leaf extract of Ficus hispida L were characterized by range of spectroscopic and microscopic techniques such as UV-Visible(UV-Vis), Fourier transform infrared (FTIR) spectroscopy, powder X-ray diffraction (XRD), Field emission scanning electron microscopy (FESEM), and Transmission electron microscopy (TEM) and Vibrating sample magnetometer (VSM). 


\subsection{Materials}

\section{Experimental}

Analytical grade Iron (II) sulfate hepta hydrate $\left(\mathrm{FeSO}_{4} \cdot 7 \mathrm{H}_{2} \mathrm{O}\right)$, Iron (III) chloride hexa hydrate $\left(\mathrm{FeCl}_{3} .6 \mathrm{H}_{2} \mathrm{O}\right), \mathrm{NH}_{3}$, Methylene blue were purchased from Merck, India and used without further purification. The leaves of Ficus hispida L. were collected from forest of Chintapalli, Andhra Pradesh, India. Milli-Q water was used throughout the synthesis process.

\subsection{Preparation of plant extract}

The fresh leaves of Ficus hispida L. washed thoroughly with running tap water and followed by Milli$\mathrm{Q}$ water to remove the dust, adhering soil and the leaves were dried under shade for 15 days and make powdered using blender. The extract was prepared by dissolving 5 grams of leaf powder in $100 \mathrm{ml}$ of Milli-Q water and boiled at $60{ }^{\circ} \mathrm{C}$ for $20 \mathrm{~min}$. Then the aqueous leaf extract was filtered through the Whatman NO.1 filter paper to separate out the broth and the filtrate was stored at $4{ }^{\circ} \mathrm{C}$ for the preparation of $\mathrm{Fe}_{3} \mathrm{O}_{4} \mathrm{NPs}$.

\subsection{Synthesis of $\mathrm{Fe}_{3} \mathrm{O}_{4} \mathrm{NPs}$}

$\mathrm{Fe}_{3} \mathrm{O}_{4}$ NPs were synthesized based on co-precipitation method in the presence of aqueous leaf extract of Ficus hispida L. as a capping agent. In a typical synthesis, 2:1 molar ratio of $\mathrm{FeCl}_{3} \cdot 6 \mathrm{H}_{2} \mathrm{O}(0.11 \mathrm{~g})$ and $\mathrm{FeSO}_{4} .7 \mathrm{H}_{2} \mathrm{O}(0.556 \mathrm{~g})$ were dissolved in a $85 \mathrm{~mL}$ Milli-Q water under ultrasonication in a $250 \mathrm{~mL}$ Erlenmeyer flask at room temperature. Then the reaction was allowed for 60 minutes to proceeded at $80^{\circ} \mathrm{Cwith}$ constant stirring under nitrogen atmosphere .Then, $10 \mathrm{~mL}$ of $5 \%$ aqueous leaf extract of Ficus hispida L. was quickly added in to the above reaction mixture and $5 \mathrm{~mL}$ of $25 \% \mathrm{NH}_{3}$ was added drop wise to the reaction mixture to adjust the $\mathrm{pH}=10$.The formation of $\mathrm{Fe}_{3} \mathrm{O}_{4} \mathrm{NPs}$ was marked by the appearance of a black precipitate, and the $\mathrm{Fe}_{3} \mathrm{O}_{4} \mathrm{NPs}$ were separated by centrifuging at $5000 \mathrm{rpm}$. The product was washed periodically with Milli-Q water and ethanol and then dried in the vacuum at room temperature.

\subsection{Characterization}

The absorption spectra of as prepared $\mathrm{Fe}_{3} \mathrm{O}_{4} \mathrm{NPs}$ were recorded using a Shimadzu (2450 SHIMADZU) spectrometer. Fourier transform-infrared (FTIR) spectra were recorded in the range of 4000-400 $\mathrm{cm}^{-1}$ with a SHIMADZU-IR PRESTIGE-2 Spectrometer. Powder samples were mixed thoroughly with potassium bromide $(\mathrm{KBr})$ and pressed into thin pellets. The powder X-ray diffraction (XRD) patterns were obtained by PANalytical X'pert pro diffractometer at 0.02 degree/sec scan rate with $\mathrm{Cu}-\mathrm{k} \alpha_{1}$ radiation $(1.5406$ $\mathrm{A}^{0}, 45 \mathrm{kV}, 40 \mathrm{~mA}$ ). Morphology of $\mathrm{Fe}_{3} \mathrm{O}_{4} \mathrm{NPs}$ was investigated by using FESEM (FESEM, Zeiss Ultra-60) equipped with X-ray energy dispersive spectroscopy (EDS). TEM images were obtained (TEM model FEI Technai $20 \mathrm{U}$ Twin) at an accelerating voltage of 120 and $200 \mathrm{kV}$. The room temperature magnetization of $\mathrm{Fe}_{3} \mathrm{O}_{4} \mathrm{NPswas}$ measured using vibrating sample magnetometer (VSM Lakeshore 665, USA ).

\subsection{Batch mode adsorption studies}

Batch adsorption efficiency of synthesized $\mathrm{Fe}_{3} \mathrm{O}_{4} \mathrm{NPs}$ experiments was carried out at room temperature $(300 \mathrm{~K})$ using Methylene Blue as a model water pollutant. Typically, $50 \mathrm{mg}$ of $\mathrm{Fe}_{3} \mathrm{O}_{4} \mathrm{NPs}$ was mixed with 50 $\mathrm{mL}$ of known concentration of dye solution. The solution $\mathrm{pH}$ was adjusted by $\mathrm{HCl}(0.1 \mathrm{M})$ or $\mathrm{NaOH}(0.1 \mathrm{M})$. The flasks were stirred for the specified time period and sample from each flask was withdrawn at the desired time of reaction. The synthesized $\mathrm{Fe}_{3} \mathrm{O}_{4} \mathrm{NPs}$ were recovered by an external magnet. The residual dye concentration was determined by UV-Visible spectrophotometer by measuring the absorbance at a wavelength of maximum $\left(\lambda_{\max }=664 \mathrm{~nm}\right)$ absorbance of MB. The amount of adsorbed MB (q) onto synthesized $\mathrm{Fe}_{3} \mathrm{O}_{4} \mathrm{NPs}$ was expressed in $\mathrm{mg}$ of dye per gram of $\mathrm{Fe}_{3} \mathrm{O}_{4} \mathrm{NPs}$, as shown in the Eq. (1):

$$
\mathrm{q}=\left(\mathrm{C}_{0}-\mathrm{C}\right) * \mathrm{~V} / \mathrm{m}
$$

Where $\mathrm{q}$ is adsorption capacity of $\mathrm{MB}$ in $\left(\mathrm{mg} \cdot \mathrm{g}^{-1}\right)$ at time $\mathrm{t}, \mathrm{C}_{0}$ represents the initial $\mathrm{MB}$ concentration in $\mathrm{mg} . \mathrm{L}^{-1}, \mathrm{C}$ is the concentration of $\mathrm{MB}$ in $\mathrm{mg} / \mathrm{L}$ after adsorption at a time ' $\mathrm{t}$ ', $\mathrm{V}$ is the volume of MB solution in $\mathrm{L}$, and $\mathrm{m}$ is the mass of synthesized $\mathrm{Fe}_{3} \mathrm{O}_{4}$ NPs in grams. The adsorption phenomenon was evaluated by adsorption isotherms and kinetic models

\section{Result And Discussion}

$\mathrm{Fe}_{3} \mathrm{O}_{4} \mathrm{NPs}$ were prepared via co-precipitation method by adding a base $\left(25 \% \mathrm{NH}_{3}\right)$ to an aqueous mixture of $\mathrm{Fe}^{3+}$ and $\mathrm{Fe}^{2+}$ salts at a 2:1 molar ratio in presence of the aqueous leaf extract of Ficus hispida $\mathrm{L}$. The phytochemicals present in the aqueous leaf extract of Ficus hispida L. are responsible for the formation of $\mathrm{Fe}_{3} \mathrm{O}_{4}$ NPs. After addition of $25 \% \mathrm{NH}_{3}$ and stirring the reaction mixture for $1 \mathrm{~h}$, the colour of the reaction mixture of $\mathrm{Fe}^{2+}$ and $\mathrm{Fe}^{+3}$ salts and aqueous leaf extract of Ficus hispida L. turned from light rose red to black, which indicates the formation of $\mathrm{Fe}_{3} \mathrm{O}_{4}$ NPs. The UV-Vis absorption spectra of synthesized $\mathrm{Fe}_{3} \mathrm{O}_{4} \mathrm{NPs}$ and aqueous 
leaf extract of Ficus hispida L. were depicted in Fig 2. The aqueous leaf extract of Ficus hispida L. has a strong absorption bands at 235 and $265 \mathrm{~nm}$ which are attributed to the presence of terpenoids, alkaloids, phenolic acid, flavoniod, tannins and carbohydrates in aqueous extract. The characteristic absorption band at $379 \mathrm{~nm}$ indicates the formation of $\mathrm{Fe}_{3} \mathrm{O}_{4} \mathrm{NPs}$ which is primarily due to the absorption and scattering of light by $\mathrm{Fe}_{3} \mathrm{O}_{4} \mathrm{NPs}$. Moreover, the absence of the leaf extract peak of Ficus hispida L. at 235 and $265 \mathrm{~nm}$ in the $\mathrm{Fe}_{3} \mathrm{O}_{4}$ NPs spectrum clearly indicates terpenoids, alkaloids, phenolic acid, flavoniod, tannins and carbohydrates phytochemicals act as reducing and capping agent for synthesis of $\mathrm{Fe}_{3} \mathrm{O}_{4}$ NPs.

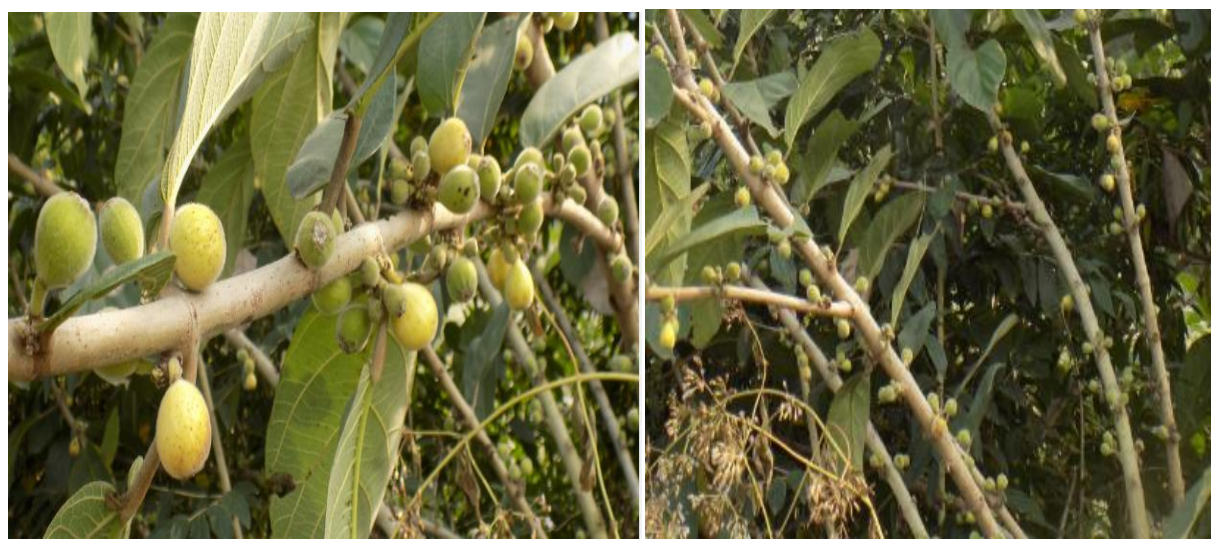

Fig. 1 Images of of Ficus hispida L plant

The plant Ficus hispida L. belongs to the Moraceae family and its leaves used as an indigenous traditional medicine [26]. The extracts of all parts of the plant have been reported to be antidysenteric and to have activity against jaundice, hypoglycemic activity,antidiabetic activity and hemorrhage [27-29]. Leaf extract of Ficus hispida L. contains alkaloids, carbohydrates, proteins, amino acids, sterols, phenols, flavonoids, glycosides, saponins, and terpenes. Phytochemicals present in leaf extract of Ficus Hispida L. can used as reducing and capping agent for the formation of magnetite nanoparticles.

\subsection{UV-Vis, XRD Characterization of as prepared $\mathrm{Fe}_{3} \mathrm{O}_{4} \mathrm{NPs}$}

The UV-Vis absorption spectra of both aqueous leaf extract of Ficus hispida L. and synthesized $\mathrm{Fe}_{3} \mathrm{O}_{4}$ NPs were depicted in Fig 2. The characteristic absorption peak observed at $379 \mathrm{~nm}$ which indicates the formation of $\mathrm{Fe}_{3} \mathrm{O}_{4} \mathrm{NPs}$. As the concentration of bark extract increases, the absorption intensity of synthesized $\mathrm{Fe}_{3} \mathrm{O}_{4}$ NPs also increases.

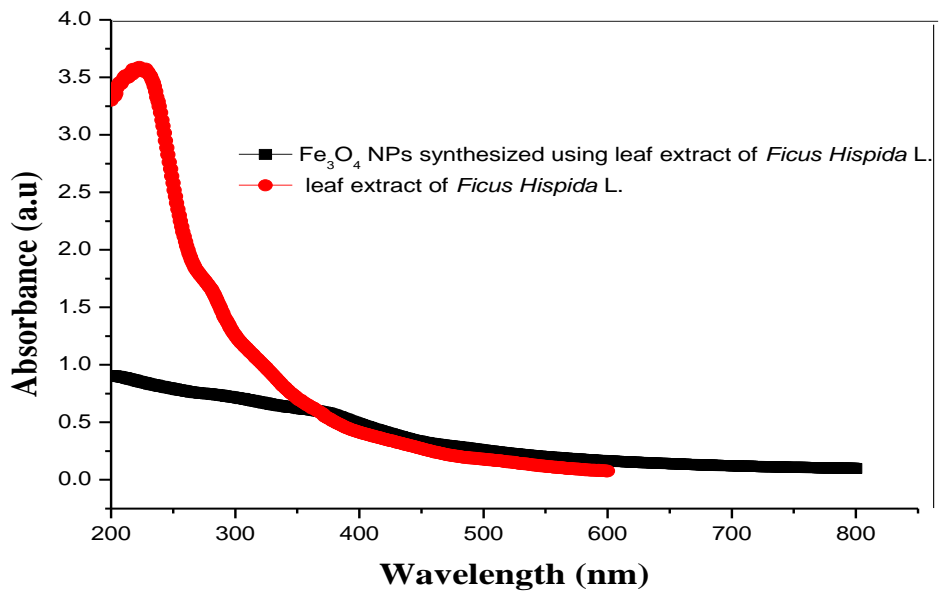

Fig .2 The UV-vis spectra of $5 \%$ aqueous leaf extract of Ficus hispida L. and $\mathrm{Fe}_{3} \mathrm{O}_{4} \mathrm{NPs}$ synthesized using $5 \%$ aqueous leaf extract of Ficus hispida L. . at $350 \mathrm{~K}$, and $\mathrm{P}^{\mathrm{H}}=10$ respectively.

The crystalline nature of $\mathrm{Fe}_{3} \mathrm{O}_{4} \mathrm{NPs}$ was confirmed using powder XRD. The XRD pattern of $\mathrm{Fe}_{3} \mathrm{O}_{4}$ NPs synthesized using aqueous leaf extract of Ficus hispida L. was shown in Fig 3. The Bragg reflection peaks were observed at $2 \theta$ values of $30.19,35.736,43.40,53.8,57.37,62.93,74.7$ which could be indexed to 
(220),(311), (400), (422),(511), (440) and (533) planes of inverse cubic spinel phase of pure $\mathrm{Fe}_{3} \mathrm{O}_{4} \mathrm{NPs}$ (JCPDS 19-0629). The intense reflection at (311) plane in contrast to the other of planes may specify the growth direction of the nanocrystals.

The average crystallite sizes of the $\mathrm{Fe}_{3} \mathrm{O}_{4} \mathrm{NPs}$ were estimated by the Scherrer equation

$$
\mathrm{D}=\mathrm{k} \lambda / \beta \cos \theta
$$

Where $\mathrm{D}$ is particle diameter size, $\mathrm{K}$ is a constant equals $1, \lambda$ is wavelength of $\mathrm{X}$-ray source $(0.1541 \mathrm{~nm}), \beta$ is the full width at half maxima (FWHM) and $\theta$ is the diffraction angle corresponding to the lattice plane The average crystallite size of $\mathrm{Fe}_{3} \mathrm{O}_{4} \mathrm{NPs}$ according to Scherrer equation with the width of (311) plane is found to be11.04 $\mathrm{nm}$.

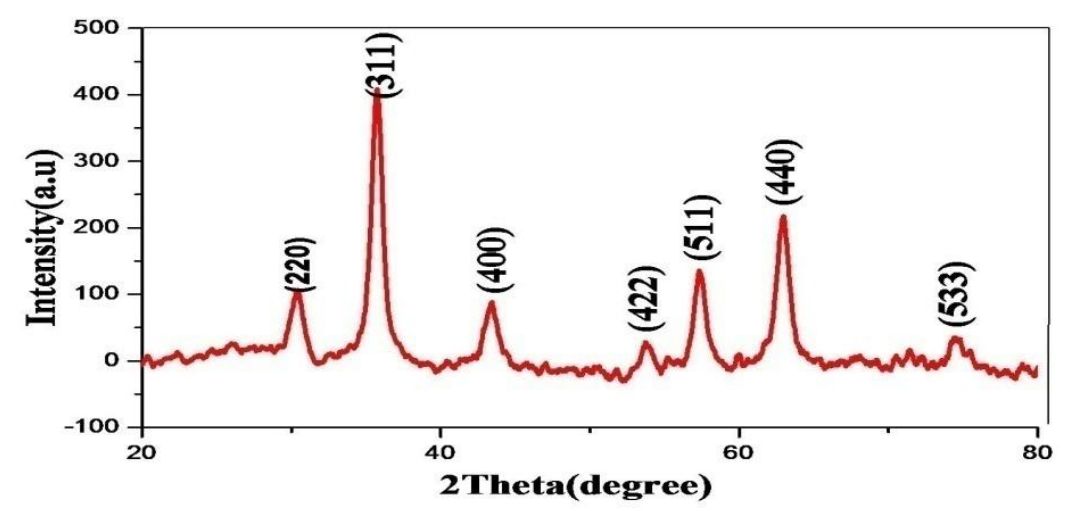

Fig. 3 Powder XRD patterns of $\mathrm{Fe}_{3} \mathrm{O}_{4}$ NPs synthesised using aqueous leaf extract of Ficus hispida L.

\subsection{Morphology}

Surface morphology as synthesised $\mathrm{Fe}_{3} \mathrm{O}_{4} \mathrm{NPs}$ was investigated by FESEM and TEM. Representative FESEM images of $\mathrm{Fe}_{3} \mathrm{O}_{4}$ NPs depicts in Fig.4 (a-c). FESEM images of $\mathrm{Fe}_{3} \mathrm{O}_{4}$ NPs show spherical shape. Fig 5(d) show the EDS spectrum of $\mathrm{Fe}_{3} \mathrm{O}_{4} \mathrm{NPs}$ and it shows that the presence of $\mathrm{Fe}$ and $\mathrm{O}$ atoms with $63.75 \%$, $29.37 \%$ weight value respectively. EDS spectrum also reveals that the presence of C (6.87) \% are the source of leaf extract of Ficus hispida L.
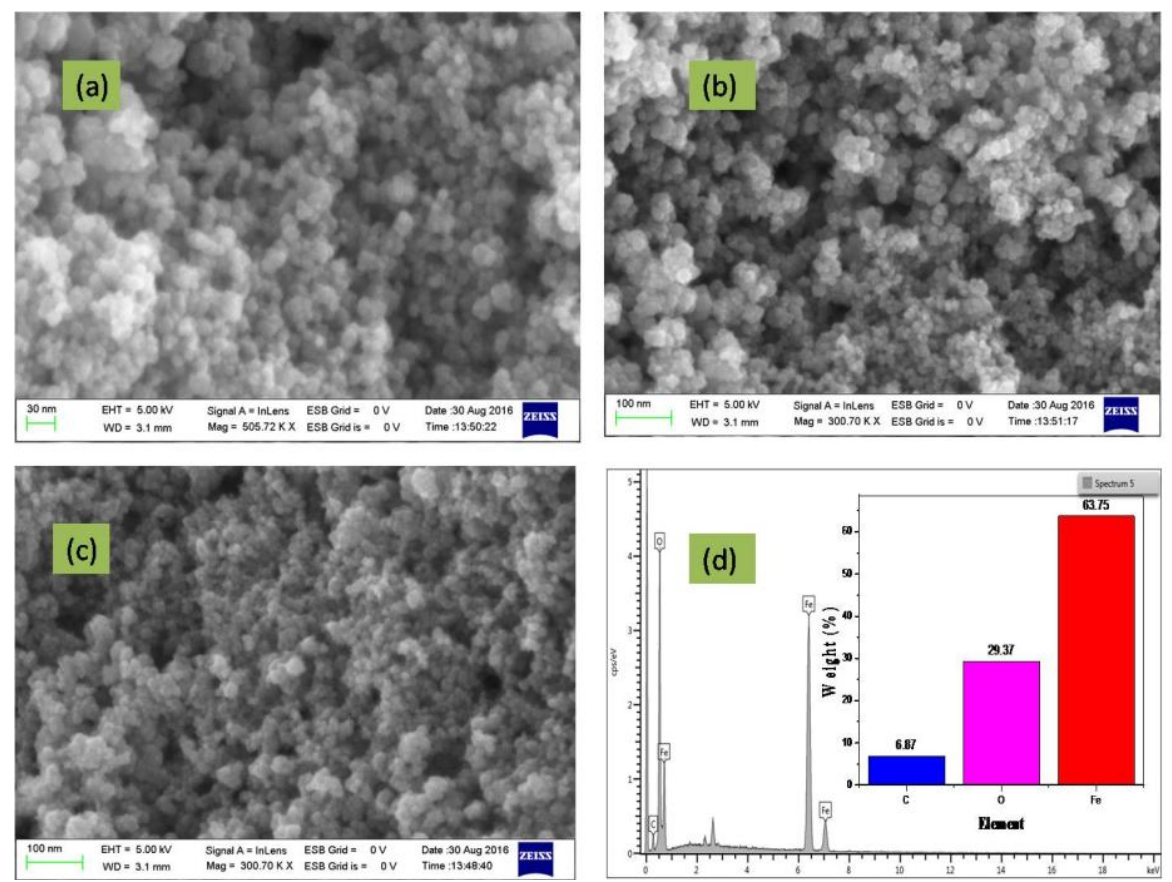

Fig.4 (a, b and c) FESEM images and (d) Energy dispersive X-ray spectroscopy (EDS) of $\mathrm{Fe}_{3} \mathrm{O}_{4} \mathrm{NPs}$ synthesized using aqueous leaf extract of Ficus hispida L. 
TEM images of $\mathrm{Fe}_{3} \mathrm{O}_{4} \mathrm{NPs}$ synthesized using aqueous leaf extract of Ficus hispida L. represent in Fig 5(a-b). As can be seen in Fig 5(a-b), the morphology of the $\mathrm{Fe}_{3} \mathrm{O}_{4} \mathrm{NPs}$ was found to be cubic morphology with an average particle size $10.96 \mathrm{~nm}$. It is very close to crystallite size (11.04). The selected area electron diffraction (SAED) pattern of the $\mathrm{Fe}_{3} \mathrm{O}_{4}$ NPs shows in Fig 5 (c). The ring-like diffraction pattern indicates that the as

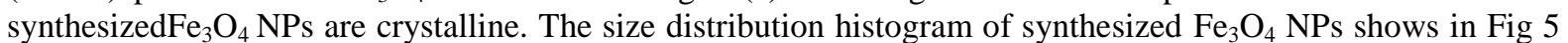
(d).
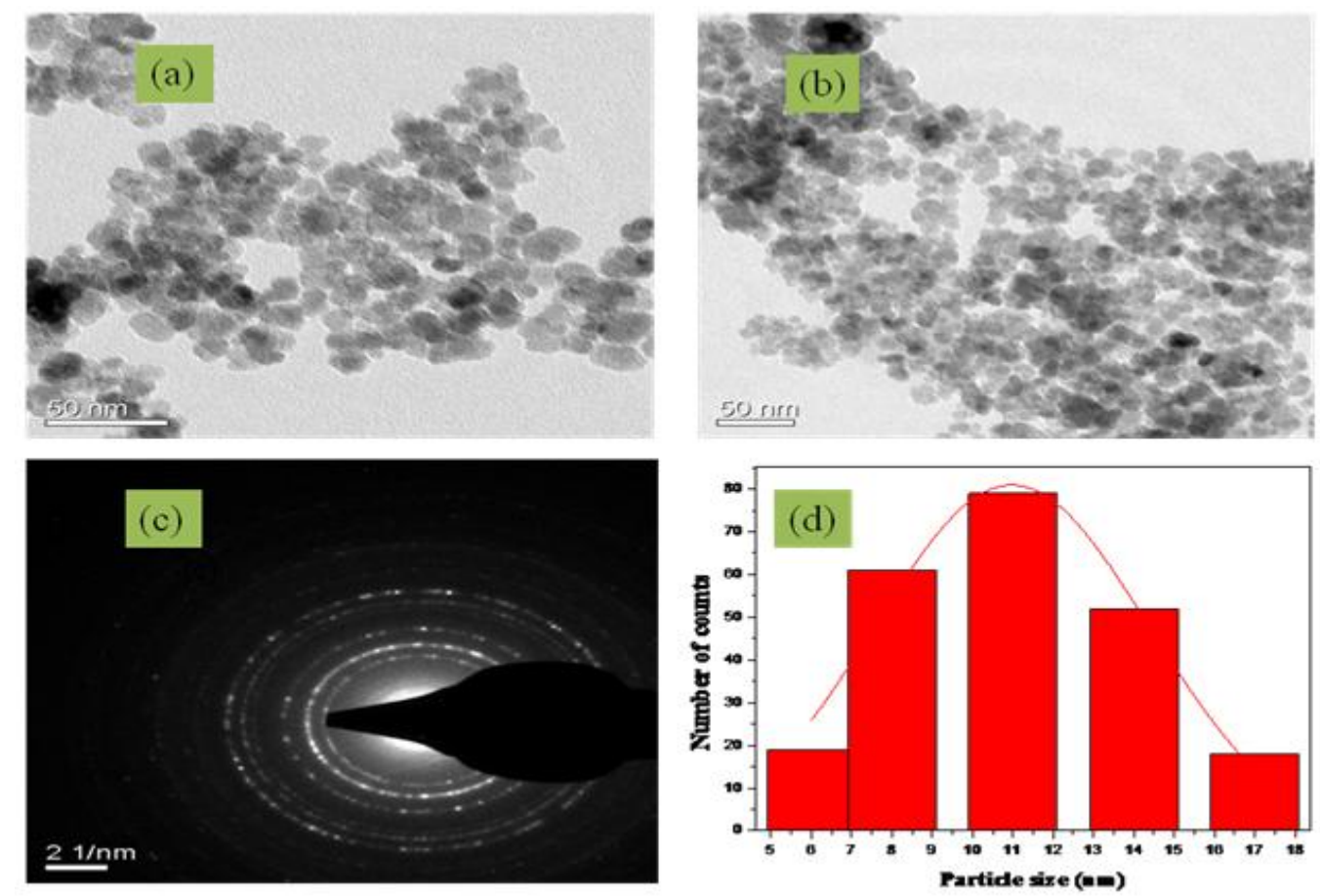

Fig 5 (a and b) Representative TEM images and (c) Selected Area Electron Diffraction (SAED) and(d) size distribution histogram of $\mathrm{Fe}_{3} \mathrm{O}_{4}$ NPs synthesized using aqueous leaf extract of Ficus hispida L.

\subsection{Magnetic property}

The magnetic property of synthesized $\mathrm{Fe}_{3} \mathrm{O}_{4}$ NPs was measured at room temperature by a Vibrating sample magnetometer (VSM). The magnetization curve of the synthesized $\mathrm{Fe}_{3} \mathrm{O}_{4} \mathrm{NPs}$ is presented in Fig.6. The sigmoidal shape of VSM curve of the synthesized $\mathrm{Fe}_{3} \mathrm{O}_{4} \mathrm{NPs}$ without hysteresis loop demonstration of super paramagnetic behaviour with the saturation magnetization (Ms) value $100 \mathrm{emu} / \mathrm{g}$ at room temperature.

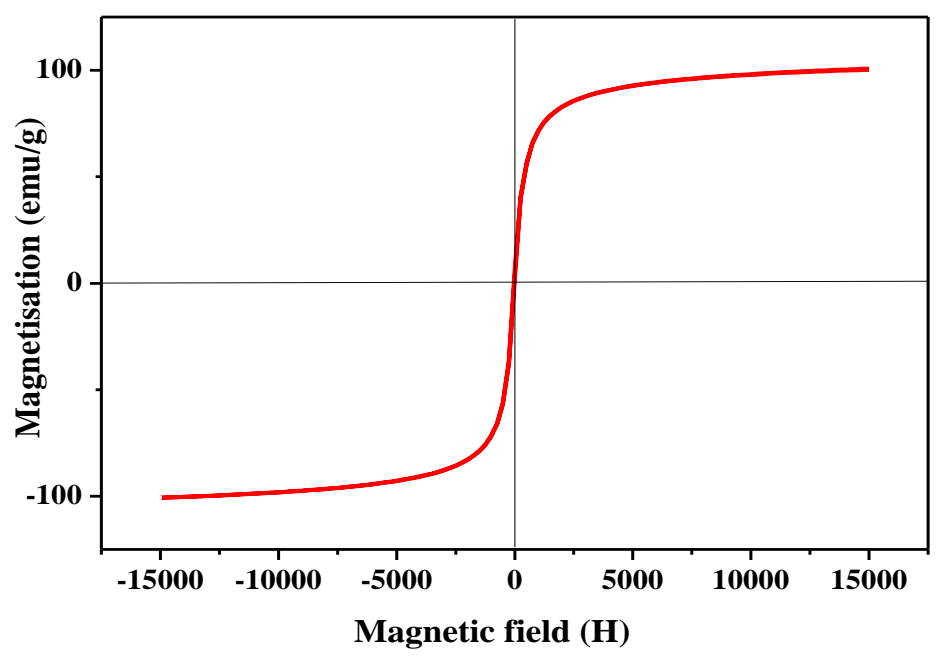

Fig. 6 The room temperature magnetization curve of $\mathrm{Fe}_{3} \mathrm{O}_{4}$ NPs synthesized using aqueous leaf extract of Ficus hispida L. 


\subsection{FTIR characterisation of as prepared $\mathrm{Fe}_{3} \mathrm{O}_{4} \mathrm{NPs}$}

FTIR spectra were recorded to identify the functionalities found on aqueous leaf extract of Ficus hispida L. and $\mathrm{Fe}_{3} \mathrm{O}_{4}$ NPs. As shown in Fig 7(a-b), both FTIR spectra of and $\mathrm{Fe}_{3} \mathrm{O}_{4}$ NPs obtained from aqueous leaf extract of Ficus hispida L. and aqueous leaf extract of Ficus hispida L. extract have close similarities, with some marginal shifts in peak position, clearly indicate the presence of phtoconstituents in the leaf extract act as a reducing and capping agent to the $\mathrm{Fe}_{3} \mathrm{O}_{4}$ NPs. The phytochemical analysis of aqueous leaf extract of Ficus hispida L. based on FTIR spectrum strongly suggested the presence of flavoniods, tannins, carbohydrates and polyphenols, apart from other phytochemicals, which were mainly responsible for the preparation of the $\mathrm{Fe}_{3} \mathrm{O}_{4} \mathrm{NPs}$. The FTIR spectrum of the aqueous leaf extract of Ficus hispida L. exhibited characteristic stretching frequencies at $3423,2926,2360,1622,1436,1315,1054,889,781,668 \mathrm{~cm}^{-1}$.

The characteristic band at $3423,2926,1622 \mathrm{~cm}^{-1}$ are ascribed to the presence of $\mathrm{O}-\mathrm{H}$ group of the phenolic compound, $\mathrm{C}-\mathrm{H}$ group of alkane, $\mathrm{C}=\mathrm{C}$ group of terpenoids respectively. In the case of synthesized $\mathrm{Fe}_{3} \mathrm{O}_{4} \mathrm{NPs}$, a there was a shift in the absorbance peak of O-H group from 3423 to $3402 \mathrm{~cm}^{-}$indicates $\mathrm{O}-\mathrm{H}$ group of the phenolic group involved in the capping of $\mathrm{Fe}_{3} \mathrm{O}_{4} \mathrm{NPs}$. There was also shift in the absorbance peak of $\mathrm{C}=\mathrm{C}$ group of terpenoids from 1622 to $1628 \mathrm{~cm}^{-1}$. Also, a characteristic additional peak formed at $584 \mathrm{~cm}^{-1}$ was observed for in the case of $\mathrm{Fe}_{3} \mathrm{O}_{4}$ NPs which are due to characteristic stretching vibration of Fe-O. Hence, FTIR analyses were suggested that the effective capping of Ficus hispida L. leaf extract to synthesized $\mathrm{Fe}_{3} \mathrm{O}_{4} \mathrm{NPs}$.

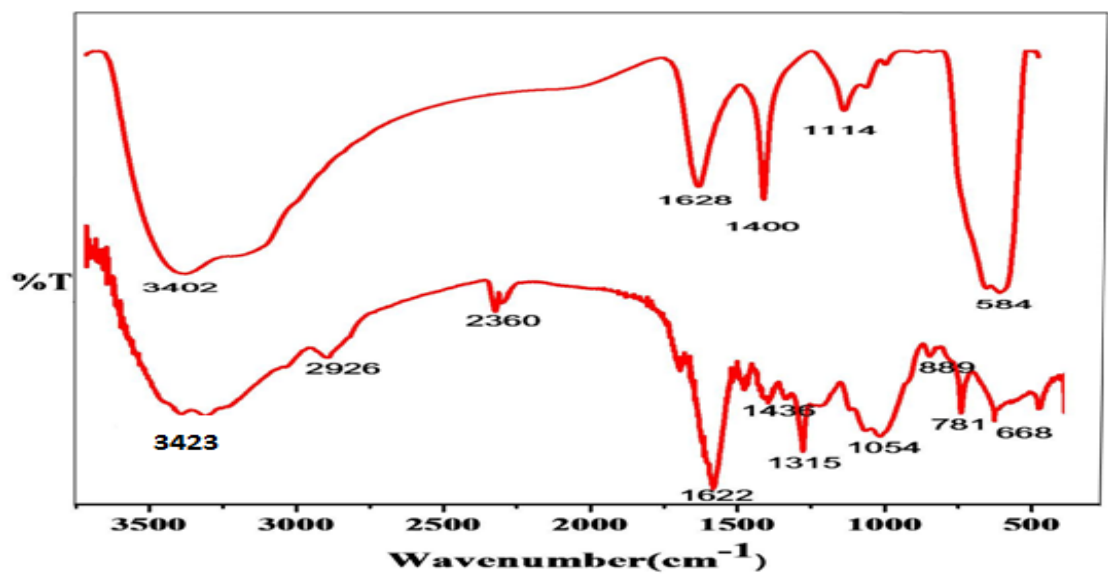

Fig. 7 FTIR spectra of (a) $\mathrm{Fe}_{3} \mathrm{O}_{4}$ NPs synthesised using aqueous leaf extract of Ficus hispida L. and (b) aqueous leaf extract of Ficus hispida L.

\section{Adsorption Studies}

The time-dependent UV-vis absorption spectra of MB in the solution at time ' $t$ ' after the adsorption by synthesized $\mathrm{Fe}_{3} \mathrm{O}_{4}$ NPs is shown in Fig. 8. The adsorption after 180 min there was not observed a further reduction of MB peak at $664 \mathrm{~nm}$ which ascribed to adsorption equilibrium was attained at the end of $180 \mathrm{~min}$. Fig. 9 (a-b) is depicted that at the adsorption equilibrium (180 min), adsorption of $\mathrm{Fe}_{3} \mathrm{O}_{4} \mathrm{NPs}$ for $\mathrm{MB}$ [at $300 \mathrm{~K}$, $\mathrm{pH}=11$, were found to be $91 \%, 89 \%, 80 \%$ for concentration of $5 \mathrm{mgL}^{-1}, 10 \mathrm{mgL}^{1}, 15 \mathrm{mLL}^{-1} \mathrm{MB}$ respectively.

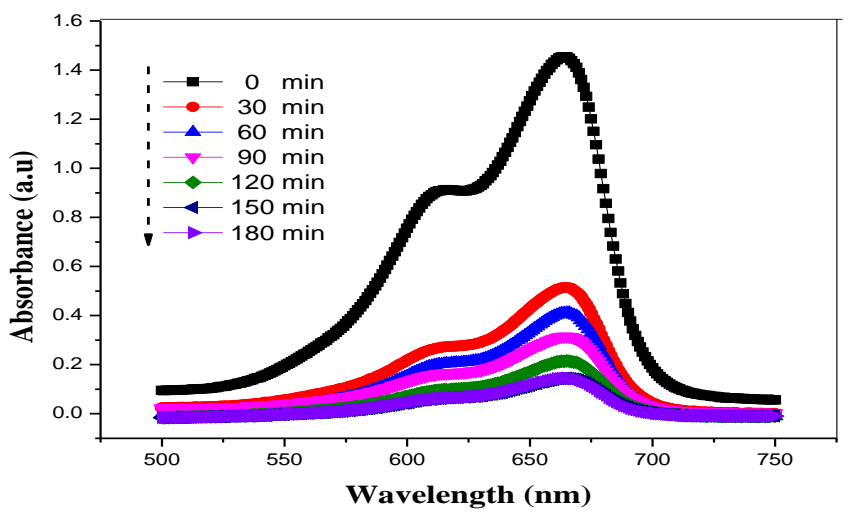

Fig.8 The UV-Vis absorption spectra of MB $\left(10 \mathrm{mgL}^{-1}\right)$ adsorbed by synthesized $\mathrm{Fe}_{3} \mathrm{O}_{4} \mathrm{NPs}$ at different time 

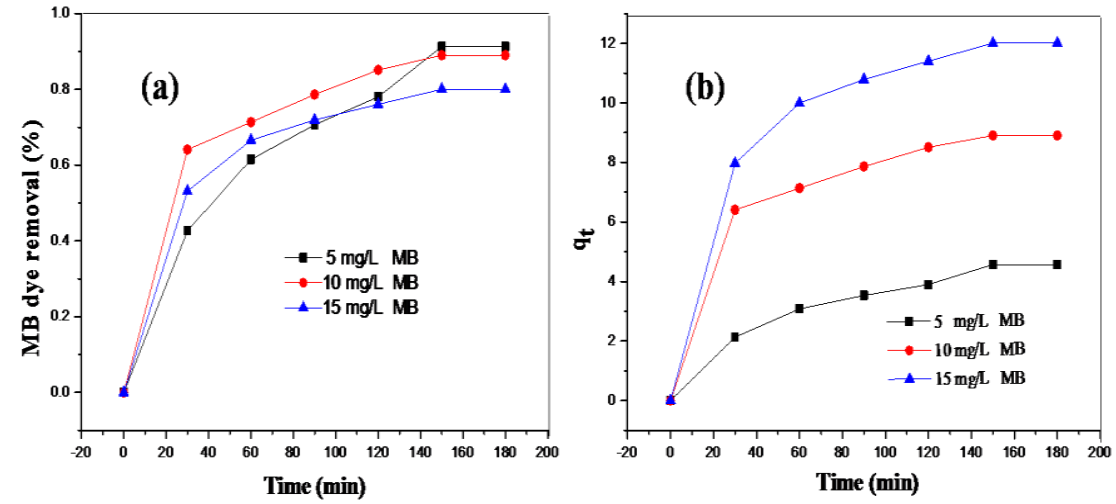

Fig.9 (a) The percentage (\%) of dye adsorption removal, and (b) the amount of MB dye adsorbed (q in mg.L $\mathrm{L}^{-1}$ ) at various concentration of $\mathrm{MB}$ onto $\mathrm{Fe}_{3} \mathrm{O}_{4} \mathrm{NPs}$.

\subsection{Adsorption kinetics}

The adsorption kinetics of MB on synthesized $\mathrm{Fe}_{3} \mathrm{O}_{4} \mathrm{NPs}$ was conducted at a different concentration of MB. Fig. 9(a-b) shows that the adsorption rate of MB on to synthesized $\mathrm{Fe}_{3} \mathrm{O}_{4}$ NPs at a different initial concentration of $5 \mathrm{mgL}^{-1}, 10 \mathrm{mgL}^{-1}, 15 \mathrm{mgL}^{-1}$ of $\mathrm{MB}$ (at $\mathrm{pH}=11$ and $300 \mathrm{~K}$ ). As shown in Fig. 9(b), the adsorption process was fast for the first 30 minuets and gradually reached to equilibrium at the end of $180 \mathrm{~min}$. The kinetics of adsorption of MB on synthesized $\mathrm{Fe}_{3} \mathrm{O}_{4}$ NPs was investigated by pseudo-first-order [30] Eq. (3) and the pseudo-second-order Eq. (4) kinetic models. The pseudo-first-order kinetic model is described by the equation:

$$
\log \left(\mathrm{q}_{\mathrm{e}}-\mathrm{q}_{\mathrm{t}}\right)=\log \mathrm{q}_{\mathrm{e}}-\left(\mathrm{k}_{1} / 2.303\right) * \mathrm{t} \quad \text { Eq. }(3)
$$

Where $\mathrm{k}_{1}\left(\mathrm{~min}^{-1}\right)$ is the pseudo-first-order rate constant of adsorption, $\mathrm{qt}(\mathrm{mg} / \mathrm{g})$ and $\mathrm{q}_{\mathrm{e}}(\mathrm{mg} / \mathrm{g})$ are the amounts of the MB adsorbed at time $t$ and at equilibrium. $\mathrm{k}_{1}\left(\mathrm{~min}^{-1}\right)$ was determined from the slope of the plot of log (qe-qt) vs t (Fig. 10(a)) and it was obtained that the correlation coefficient value $\left(\mathrm{R}^{2}\right)$ is 0.925 .

Moreover, to validate the kinetic of adsorption of MB pseudo-second-order kinetic model was also investigated.

$$
\mathrm{t} / \mathrm{q}_{\mathrm{t}}=1 / \mathrm{k}_{2} \mathrm{q}_{\mathrm{e}}^{2}+\left(1 / \mathrm{q}_{\mathrm{e}}\right) * \mathrm{t}
$$

Where $\mathrm{k}_{2}\left(\mathrm{~g} / \mathrm{mg} \mathrm{min}^{-1}\right)$ is the pseudo-second-order rate constant, $\mathrm{q}_{\mathrm{t}}(\mathrm{mg} / \mathrm{g})$ and $\mathrm{q}_{\mathrm{e}}(\mathrm{mg} / \mathrm{g})$ are the amount of the MB adsorbed at time $t$ and at equilibrium. The values of $\mathrm{q}_{\mathrm{e}}$ and $\mathrm{k}_{2} \mathrm{can}$ be calculated from the slope and intercept of a plot of $t / q_{t}$ vs $t$ (Fig. 10 (b)). For this plot, correlation coefficient value $\left(R^{2}\right)$ was found to be 0.98897

.It is concluded that the adsorption of MB on synthesized $\mathrm{Fe}_{3} \mathrm{O}_{4} \mathrm{NPs}$ was found to be a pseudo-second-order kinetic model and this implies that the adsorption process more likely proceeds through electrostatic interaction of $\mathrm{MB}$ and surface of synthesized $\mathrm{Fe}_{3} \mathrm{O}_{4} \mathrm{NPs}$, also called by chemisorption process[31].

\subsection{Adsorption isotherm}

Adsorption isotherm analyses are employed to investigate the maximum adsorption capacity of synthesized $\mathrm{Fe}_{3} \mathrm{O}_{4} \mathrm{NPs}$. The equilibrium adsorption isotherm parameters of $\mathrm{MB}$ on synthesized $\mathrm{Fe}_{3} \mathrm{O}_{4} \mathrm{NPs}$ were analyzed using Langmuir and Freundlich isotherm models [32-33]. The Langmuir equation can be expressed as (Eq.5):

$$
\mathrm{C}_{\mathrm{e}} / \mathrm{q}_{\mathrm{e}}=\mathrm{C}_{\mathrm{e}} / \mathrm{Q}_{0}+1 / \mathrm{Q}_{0} \mathrm{~b}_{\mathrm{L}} \quad \mathrm{Eq}(5)
$$

Where $\mathrm{q}_{\mathrm{e}}(\mathrm{mg} / \mathrm{g})$ is the equilibrium adsorption capacity of $\mathrm{MB}$ on the adsorbent, $\mathrm{C}_{\mathrm{e}}(\mathrm{mg} / \mathrm{L})$ is the equilibrium concentration of $\mathrm{MB}$ in the solution, $\mathrm{Q}_{0}(\mathrm{mg} / \mathrm{g})$ is the maximum capacity of adsorbent, and $\mathrm{b}$ $(\mathrm{L} / \mathrm{mg})$ is the equilibrium constant relating to the enthalpy of process. Fig.10(c) shows that the experimental data well fitted to the Langmuir adsorption isotherm and it was found to be $16.39344 \mathrm{mg} / \mathrm{g}$ maximum adsorption capacity. The correlation coefficient $\left(\mathrm{R}^{2}\right)$ and equilibrium constant $\left(\mathrm{b}_{\mathrm{L}}\right)$ values were found to be 0.9875 and 0.98387 respectively. Besides, dimensionless factor $\left(\mathrm{R}_{\mathrm{L}}\right)$ of the Langmuir adsorption isotherm parameter calculates using Eq. 5. The $\mathrm{R}_{\mathrm{L}}$ value was obtained 0.179618 which is in between 0 and 1 . This indicates that the adsorption of $\mathrm{MB}$ on $\mathrm{Fe}_{3} \mathrm{O}_{4} \mathrm{NPs}$ is thermodynamically favorable.

$$
\mathrm{R}_{\mathrm{L}}=1 /\left(1+\mathrm{b}_{\mathrm{L}^{*}} \mathrm{C}_{0}\right)
$$

Where $\mathrm{C}_{0}(\mathrm{mg} / \mathrm{g})$ is initial MB concentration, $\mathrm{b}_{\mathrm{L}}(\mathrm{L} / \mathrm{mg})$ is the Langmuir constant. For unfavourable sorption, $\mathrm{RL}>1$; for favourable sorption, $0<\mathrm{R}_{\mathrm{L}}<1$; for irreversible sorption $\mathrm{RL}<0$; for linear sorption, $\mathrm{R}_{\mathrm{L}}<1$

The Freundlich isotherm (Eq. 7) can be expressed as: 


$$
\log \mathrm{q}_{\mathrm{e}}=\log \mathrm{k}_{\mathrm{f}}+1 / \mathrm{n} \log \mathrm{C}_{\mathrm{e}}
$$

$\mathrm{q}_{\mathrm{e}}(\mathrm{mg} / \mathrm{g})$, is the equilibrium adsorption capacity of $\mathrm{MB}$ on the synthesized $\mathrm{Fe}_{3} \mathrm{O}_{4} \mathrm{NPs}, \mathrm{k}_{\mathrm{f}}(\mathrm{mg} / \mathrm{g}), 1 / \mathrm{n}$ are Freundlich constants representing the adsorption capacity (adsorption coefficient) at unit equilibrium concentration, and adsorption intensity. The value of Freundlich constant ' $n$ ' is 2.01.For this adsorption, $n>1$ indicating that $\mathrm{MB}$ favorably adsorbed on synthesized $\mathrm{Fe}_{3} \mathrm{O}_{4} \mathrm{NPs}$. The correlation coefficient values of Langmuir model $\left(R^{2}=0.9875\right)$ more close to unity than Freundlich model $\left(R^{2}=0.8883\right)$, which indicates that the experimental data best fit with the Langmuir isotherm. The monolayer adsorption maximum adsorption capacity $\left(\mathrm{Q}_{0}\right)$ of synthesized $\mathrm{Fe}_{3} \mathrm{O}_{4} \mathrm{NPs}$ was found to be $16.39344 \mathrm{mg} / \mathrm{g}$. This figure indicates that the Ficus hispida $\mathrm{L}$. assisted synthesized $\mathrm{Fe}_{3} \mathrm{O}_{4}$ NPs has comparative adsorption efficiency towards organic dyes.
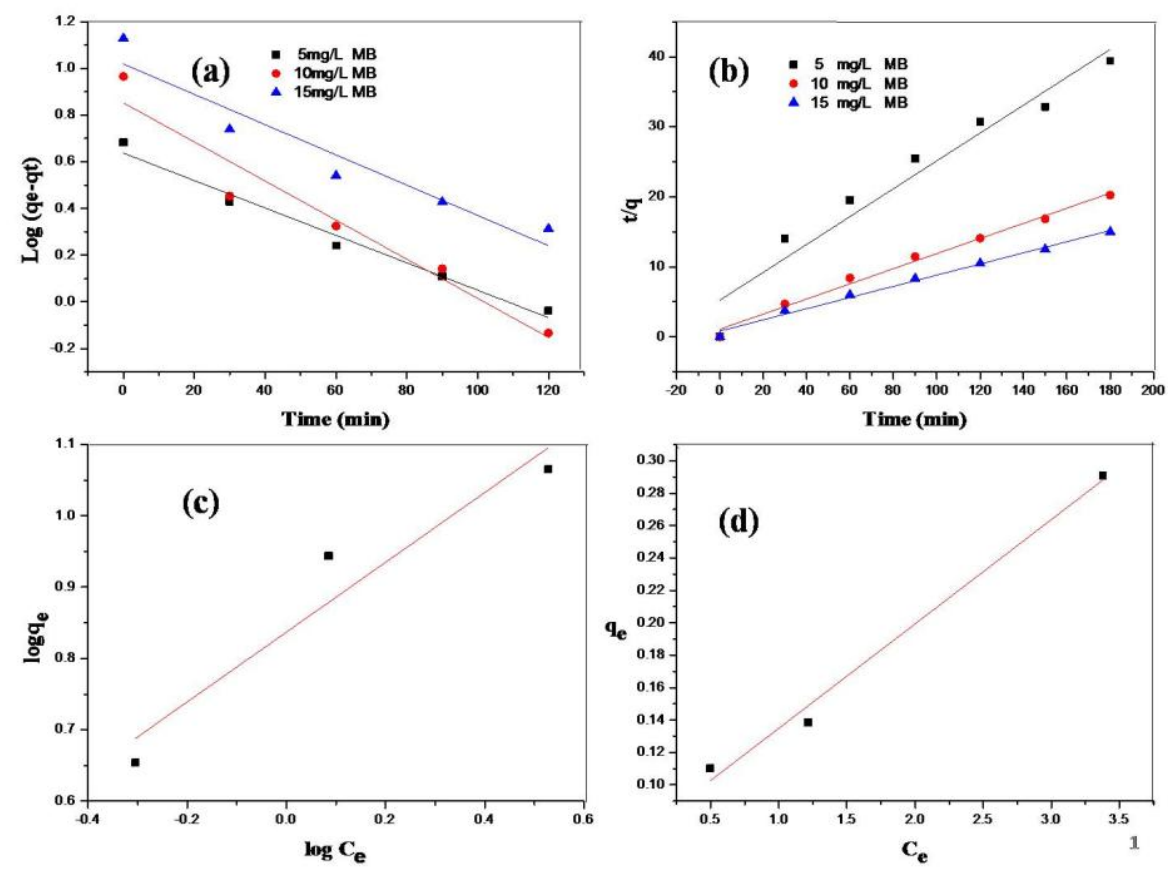

Fig.10 (a) Pseudo-first-order, (b) Pseudo-first-order kinetics plots, (c) Freundlich and (d) Langmuir adsorption isotherm plots of $\mathrm{MB}$ adsorption to synthesised $\mathrm{Fe}_{3} \mathrm{O}_{4} \mathrm{NPs}$.

Table 1: The kinetic parameters calculated from Pseudo-first and Pseudo second order kinetics model on adsorption of MB onto the synthesized $\mathrm{Fe}_{3} \mathrm{O}_{4} \mathrm{NPs}$

\begin{tabular}{|c|c|c|c|}
\hline \multirow[t]{2}{*}{ Parameters } & \multicolumn{3}{|c|}{ Initial concentration of dye } \\
\hline & $5 \mathrm{ppm}$ & $10 \mathrm{ppm}$ & $15 \mathrm{ppm}$ \\
\hline$q_{e}$, exp. (mg.g) & 4.56643 & 8.9021 & 12.00699 \\
\hline \multicolumn{4}{|c|}{ Pseudo first order kinetics } \\
\hline $\mathbf{k}_{1}\left(\min ^{-1}\right)$ & 0.013519 & 0.019276 & 0.014923 \\
\hline $\mathrm{q}_{\mathrm{e}}$ cal $(\mathrm{mg} / \mathrm{g})$ & 4.336207 & 7.12164 & 10.43999 \\
\hline $\mathbf{R}^{2}$ & 0.97506 & 0.925 & 0.89399 \\
\hline \multicolumn{4}{|c|}{ Pseudo second order kinetics } \\
\hline$k_{2}(g / m g / m i n)$ & 0.03787 & 0.09808 & 0.094543 \\
\hline$q_{e}$ cal $(\mathbf{m g} / \mathbf{g})$ & 5.027652 & 9.263548 & 12.54705 \\
\hline $\mathbf{R}^{2}$ & 0.93528 & 0.98897 & 0.9897 \\
\hline
\end{tabular}

Table 2: The Langmuir and Freundlich adsorption Isotherm parameters for adsorption of MB on synthesized

\begin{tabular}{lccc}
\multicolumn{4}{c}{$\mathrm{Fe}_{3} \mathrm{O}_{4} \mathrm{NPs}$} \\
\hline Isotherm models & \multicolumn{4}{c}{ Parameters } \\
\hline Langmuir Isotherm & $\mathrm{Q}_{0}(\mathrm{mg} / \mathrm{g})$ & $\mathrm{b}_{\mathrm{L}}(\mathrm{L} / \mathrm{mg})$ & $\mathrm{R}^{2}$ \\
& $\mathbf{1 6 . 3 9 3 4 4}$ & $\mathbf{0 . 9 8 3 8 7}$ & $\mathbf{0 . 9 8 7 5}$ \\
Freundlich Isotherm & $\mathbf{1 / n}$ & $\mathbf{k}_{\mathbf{f}}\left(\mathbf{m g}^{-1 / 1 / \mathbf{n}} \mathbf{L}^{1 / \mathbf{n}} \mathbf{g}^{-1}\right)$ & $\mathbf{R}^{\mathbf{2}}$ \\
& $\mathbf{0 . 4 9 7}$ & $\mathbf{7 . 4 1 3 1 0 2}$ & $\mathbf{0 . 8 8 8 3}$ \\
\hline
\end{tabular}

\section{Conclusion}

We have synthesized for the first time $\mathrm{Fe}_{3} \mathrm{O}_{4}$ NPs using aqueous leaves extract of Ficus hispida $\mathrm{L}$. The synthesised $\mathrm{Fe}_{3} \mathrm{O}_{4}$ NPs have shown characteristic absorption band at $379 \mathrm{~nm}$. XRD study of the synthesised $\mathrm{Fe}_{3} \mathrm{O}_{4}$ NPs has shown cubic inverse spinel structure with crystallite sizes of $11.04 \mathrm{~nm}$. The FESEM and TEM images were clearly shown that the spherical shape of $\mathrm{Fe}_{3} \mathrm{O}_{4} \mathrm{NPs}$ with average particles size of $10.96 \mathrm{~nm}$. The 
obtained magnetite nanoparticles exhibited super paramagnetic behaviour with the saturation magnetization (Ms) value $100 \mathrm{emu} / \mathrm{g}$ at room temperature. The synthesized $\mathrm{Fe}_{3} \mathrm{O}_{4} \mathrm{NPs}$ have potential to adsorption of MB.

\section{Acknowledgements}

The author is grateful to UGC-SERO, Hyderabad for awarding teacher fellowship under FDP, XII plan of UGC,

\section{References}

[1]. Miller, M.M.; Prinz, G.A.; Cheng, S.F.; Bounnak, S. Detection of a micron-sized magnetic sphere using a ring-shaped anisotropic magnetoresistance-based sensor: A model for a magnetoresistance-based biosensor. Appl. Phys. Lett. 2002, 81, 22112213.

[2]. Zhang, J.L.; Wang, Y.; Ji, H.; Wei, Y.G.; Wu, N.Z.; Zuo, B.J.; Wang, Q.L. Magnetic nanocomposite catalysts with high activity and selectivity for selective hydrogenation of ortho-chloronitrobenzene. J. Catal. 2005, 229, 114-118.

[3]. Jeyadevan, B.; Chinnasamy, C.N.; Shinoda, K.; Tohji, K.; Oka, H. Mn-Zn ferrite with higher magnetization for temperature sensitive magnetic fluid. J. Appl. Phys. 2003, 93, 8450-8452.

[4]. Sun, S.H.; Murray, C.B.; Weller, D.; Folks, L.; Moser, A. Monodisperse FePt nanoparticles and ferromagnetic FePt nanocrystal superlattices. Science 2000, 287, 1989-1992

[5]. Mahdavi, M.; Ahmad, M.B.; Haron, M.J.; Gharayebi, Y.; Shameli, K.; Nadi, B. Fabrication and characterization of SiO2/(3aminopropyl) triethoxysilane-coated magnetite nanoparticles for lead (II) removal from aqueous solution. J. Inorg. Organomet. Polym. Mater. 2013, 23, 599-607.

[6]. JGuoa, J.; Wanga, R.; Tjiu, W.W.; Pan, J.; Liu, T. Synthesis of Fe nanoparticles@ graphene composites for environmental applications. J. Hazard. Mater. 2012, 225-226, 63-73.

[7]. Guptaa, A.K.; Gupta, M. Synthesis and surface engineering of iron oxide nanoparticles for biomedical applications. Biomaterials 2005, 26, 3995-4021.

[8]. JGuoa, J.; Wanga, R.; Tjiu, W.W.; Pan, J.; Liu, T. Synthesis of Fe nanoparticles@ graphene composites for environmental applications. J. Hazard. Mater. 2012, 225-226, 63-73.

[9]. U. Jeong, X.W. Teng, Y. Wang, H. Yang, Y.N. Xia, Advanced Materials 12 (1) (2007) 33-60.

[10] Y. Zhao, Z. Qiu, J. Huang, Chinese Journal of Chemical Engineering 16 (3) (2008) 451-455.

[11] B. Mao, Z. Kang, E. Wang, S. Lian, L. Gao, C. Tian, C. Wang, Materials Research Bulletin 41 (2006) 2226.

[12] K. Woo, J. Hong, J.P. Ahn, Journal of Magnetism and Magnetic Materials 293 (2005) 177.

[13] U.T. Lam, R. Mammucari, K. Suzuki, N.R. Foster, Industrial and Engineering Chemistry Research 47 (3) (2008) 599-614.

[14] R.P. Bagwe, J.R. Kanicky, B.J. Palla, P.K. Patanjali, D.O. Shah, Critical Reviews in Therapeutic Drug Carrier Systems 18 (1) (2001) 77-140.

[15] F. Fievet, J.P. Lagier, B. Blin, B. Beaudoin, M. Figlarz, Solid State Ionics 198 (1989) 32.

[16] H.R. Kahn, K. Petrikowski, Journal of Magnetism and Magnetic Materials 215-216 (2000) 526.

[17] C. Prcharroman, T. Gonzalez-Carreno, J.E. Iglesias, Physics and Chemistry of Minerals 22 (1995) 21.

[18] S. Veintemillas-Vendaguer, M.P. Morales, O. Bomati-Miguel, C. Batista, X. Zhao, P. Bonville, R.P. Alejo, J. Ruiz-Cabello, M. Santos, J. Tendillo-Cortijo, J. Ferreiros, Journal of Physics 37 (2004) 2054.

[19] V.F. Puntes, K.M. Krishnan, A.P. Alivisatos, Topics in Catalysis 19 (2002) 145.

[20] H.G. Rotstein, R. Tannenbaum, Journal of Physical Chemistry B 106 (2002) 146.

[21] Senthil M, Ramesh C (2012) Biogenic synthesis of $\mathrm{Fe}_{3} \mathrm{O}_{4}$ nanoparticles using Tridax procumbens leaf extract and its antibacterial activity on pseudomonas aeruginosa. Dig J Nanomater Biostruct 7(4):1655-1659

[22] Basavegowda N, Magar KBS, Mishra K, Lee YR (2014) Green fabrication of ferromagnetic Fe $\mathrm{O}_{4}$ nanoparticles and their novel catalytic applications for the synthesis of biologically interesting benzoxazinone and benzthioxazinone derivatives. New $\mathrm{J}$ Chem 38(11):5415-5420

[23] Basavegowda N, Mishra K, Lee YR (2014) Sonochemically synthesized ferromagnetic $\mathrm{Fe}_{3} \mathrm{O}_{4}$ nanoparticles as a recyclable catalyst for the preparation of pyrrolo [3, 4-c] quinoline-1,3-dione derivatives. RSC Adv 4(106):61660-61666

[24] Latha N, Gowri M (2014) Biosynthesis and characterisation of $\mathrm{Fe}_{3} \mathrm{O}_{4}$ nanoparticles using Caricaya papaya leaves extract. Int $\mathbf{J}$ Sci Res 3(11):1551-1556

[25] Narayanan S, Sathy BN, Mony U, Koyakutty M, Nair SV, Menon D (2012) Biocompatible magnetite/gold nanohybrid contrast agents via green chemistry for MRI and CT bioimaging. ACS Appl Mater Interfaces 4(1):251-260

[26] Manandhar, N.P(1995) A Survey of medicinal plants of jajarkot district, Nepal. J. Ethnopharmacol., v.48, p.1-6.

[27] Nadkarni, K.M(, 1976)Indian materia medica. New Delhi: Narayana Publishersv.1, p.1031.

[28] Rastogi, R.; Mehrotra, B.N(1993)Compendium indian medicinal plants. New Delhi: CDRI, Lucknow, v.2, p.27. (Publication and Information Directorate).

[29] Sergio, R.; Peraza, S (2002) Constituents of leaves and twigs of Ficus hispida. Plant Med., v.68, p.186-188.

[30]. S. Lagergren, KungligaSvenskaVetenskapsakademiensHandlingar, 1898, 24, 1-39.

[31]. Y. Ho and G. Mckay, Process Biochemistry, 1999, 34, 451-465.

[32]. I. Langmuir, Journal of the American Chemical Society, 1916, 38, 2221-2295.

[33]. H.M.F. Freundlich, Journal of Physical Chemistry, 1906, 57, 385-471.

IOSR Journal of Applied Chemistry (IOSR-JAC) is UGC approved Journal with S1. No. 4031, Journal no. 44190.

A.V. Ramesh. "A Facile Plant Mediated Synthesis of Magnetite Nanoparticles Using Aqueous Leaf Extract of Ficus Hispida L. for Adsorption of Organic Dye." IOSR Journal of Applied Chemistry (IOSR-JAC) 10.7 (2017): 35-43. 